\title{
Modeling of Recompression Brayton Cycle And CSP Plant Architectures for Estimation of Performance \& Efficiency
}

\author{
Ashok Kumar Ravi ${ }^{1}$ Stéphane Velut ${ }^{2}$ Raja Vignesh Srinivasan ${ }^{3}$ \\ ${ }^{1}$ Modelon Engineering Private Limited, India, ashokkumar.ravi@modelon. com \\ ${ }^{2}$ Modelon AB, Sweden, stephane.velut@modelon. com \\ ${ }^{3}$ Modelon Engineering Private Limited, India, rajavignesh.srinivasan@modelon. com
}

\begin{abstract}
As the world is moving towards renewable energy sources for sustainable energy, concentrated solar power (CSP) systems with thermal energy storage present significant opportunities for generating electricity. This paper describes an effort to develop an analytic platform for Brayton cycle and connect it to central receiver CSP system to form a complete system. Already analytical model for central receiver CSP system with Rankine cycle was already developed and available with Modelon (Edman, 2015; Windahl, 2015). This paper describes the development of a supercritical $\mathrm{CO}_{2}$ recompression Brayton cycle based on the information available in the literature (Dennis, 2017). The effect of change in turbine inlet temperature on the performance and efficiency of Brayton cycle are shown. Integration of Brayton cycle with CSP system is done and the solar power requirement based on turbine inlet temperatures is studied.
\end{abstract}

Keywords: $\quad$ CSP, molten salt, Brayton cycle

\section{Introduction}

Due to the climate challenges arising because of heavy consumption of fossil fuels, lot of research is continuously being done on improving the efficiency of obtaining power through various renewable energy sources.

Concentrated solar power systems use mirrors to concentrate the solar energy. This concentrated solar power is transferred to the Molten salt and with this thermal energy storage through molten salt provides opportunity to utilize the energy during day or night as per power demand. This energy can be used in a steam generator or for Brayton cycle to generate electricity. Brayton cycle represents the operation of gas turbine engine. There is no phase change for the working fluid and fluid always remains in gaseous phase which is the reason for choosing supercritical $\mathrm{CO}_{2}$ as the working fluid. Brayton cycle provides economic advantages such as smaller system size, increased efficiency, and environmental advantages such as greenhouse gas reduction, reduced water consumption etc.
Recompression Brayton cycle which requires additional compressor and heat exchanger (HX) is better than normal Brayton cycle due to its increased efficiency. Advanced control strategies can also lead to additional benefits by optimizing the heat flow from external fluid to supercritical $\mathrm{CO}_{2}$, optimal operation of turbine and compressors under varying operating conditions. While careful design of the system is required to fully realize the benefits of Brayton cycle, there is clearly motivation to pursue given its economic and environmental benefits.

System modeling with Modelica language has been widely used for thermal power cycles modeling. With a powerful and flexible modeling framework and proven commercial libraries, Modelica language provides an ideal platform for architectural studies and controls prototyping for different power cycles. This paper describes an effort to develop an analytic platform for Brayton cycle and evaluate its performance under different operating conditions.

A baseline model of the system is developed with Vapor Cycle Library (Modelon AB, 2020). Results from the simulations are compared with data available in literature (Dennis, 2017). CSP system with thermal storage available in Thermal Power Library (Modelon $A B, 2020)$ is modified such that Rankine cycle or Brayton cycle can be interchanged as the working cycle. Simulations are done in similar conditions using Rankine cycle and Brayton cycle to show the advantages of modular structure. Eventually this will help the user in evaluating the CSP system with Rankine and Brayton cycles and decision making.

\section{Brayton Cycle System Model}

This section provides an overview of the Brayton cycle model. The model is based on the prototype of recompression Brayton cycle developed by National Energy Technology Laboratory (NETL) (Dennis, 2017). The following sections provide an overview of the full system model and relevant component modeling details. 


\subsection{System and Model Overview}

Brayton cycle system can be divided into low pressure and high-pressure sides as that of the Vapor cycle systems. From turbine outlet to the compressor inlet can be considered as low-pressure side, and from compressors outlet to the turbine inlet can be considered as high-pressure side. Following are the main components of the system:

- Turbine

- Main compressor

- Bypass compressor

- High temperature recuperator

- Low temperature recuperator

- Primary heater

- Cooler

Two variants of primary heaters are used based on the study. When integrated with CSP thermal storage system, counterflow heat exchanger is used with super critical $\mathrm{CO}_{2}$ and Molten salt $\left(60 \% \mathrm{NaNO}_{3} 40 \% \mathrm{KNO}_{3}\right)$ as the fluids (two phase liquid heat exchanger). During individual system studies of Brayton cycle heat is directly provided to supercritical $\mathrm{CO} 2$. Two variants of the system are shown in Figure 3 and Figure 4 respectively. Conditional routing which is possible with Modelica language is used to pass the fluid through heat exchanger or volume with heat source based on requirement. In the first variant, volume with heat source is switched off and flow is happening through the heat exchanger (primary heater) only which is shown in red box in Figure 3. When the heat exchanger sizing and performance details are available this variant can be used. In the second variant, heat exchanger component is switched off and flow is passing through volume with heat source shown in red box in Figure 4. When the user has not sized the heat exchanger and want to calculate the amount of heat transfer required for the fluid to reach different target turbine inlet temperatures, this variant is very useful.

High temperature recuperator (HTR) and low temperature recuperator (LTR) are used for recovering the heat of the fluid coming out of the turbine. This increases the thermal efficiency of the system. In HTR, turbine outlet fluid interacts with the high-pressure fluid mixture coming out of bypass compressor and the secondary side of LTR. In LTR, fluid coming out of the HTR interacts with the fluid coming out of the main compressor. Fluid coming out of the LTR primary side is divided and sent through main and bypass compressors.

Flow through the bypass compressor is set such that more efficient heat recuperation happens, thereby higher cycle efficiency is achieved. Before sending the flow through the first compressor, fluid is cooled down to $35^{\circ} \mathrm{C}$. In the current model heat is removed directly using controller such that the inlet temperature at the main compressor inlet is $35^{\circ} \mathrm{C}$. Fluid inlet conditions to the bypass compressor are same as that of the exit conditions of the LTR.

After passing through the compressors and then the recuperators, high pressure fluid is provided with more heat such that the required electric power is generated.

\subsection{System Characterization}

One of the main challenges in building the model of the Brayton cycle system is the lack of data to parameterize the components and characterize the system outside of publicly available data in literature. This data along with knowledge of similar systems was used to get a reasonable, first cut system model though is admittedly imperfect and not desirable for model accuracy.

Compressors, turbine, and recuperators are the key components in the system. Dynamic compressor model based on look-up tables for isentropic efficiency and corrected mass flow rate is used for modeling the compressor. As we have one set of operating condition for the entire system based on literature (Dennis, 2017), that point is considered as the design point. Considering this as design point isentropic efficiency and mass flow rate maps (Figure 1, Figure 2, Figure 5, Figure 6) are generated which are shown below:

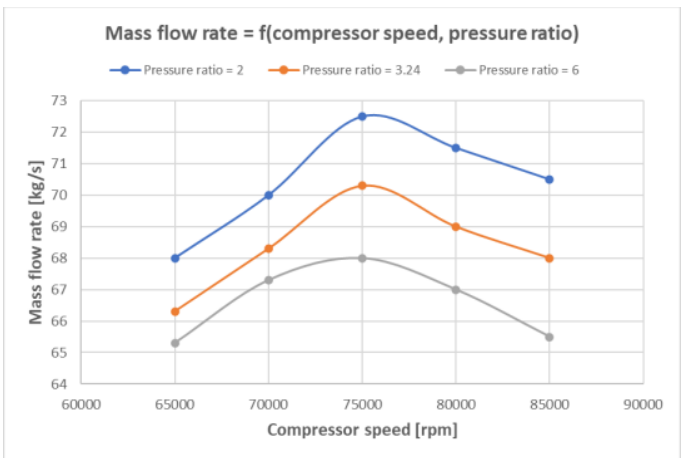

Figure 1. Main compressor mass flow map

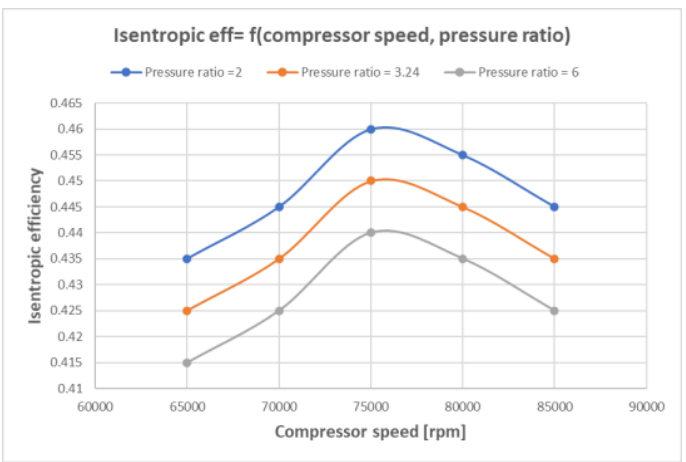

Figure 2. Main compressor isentropic eff map 


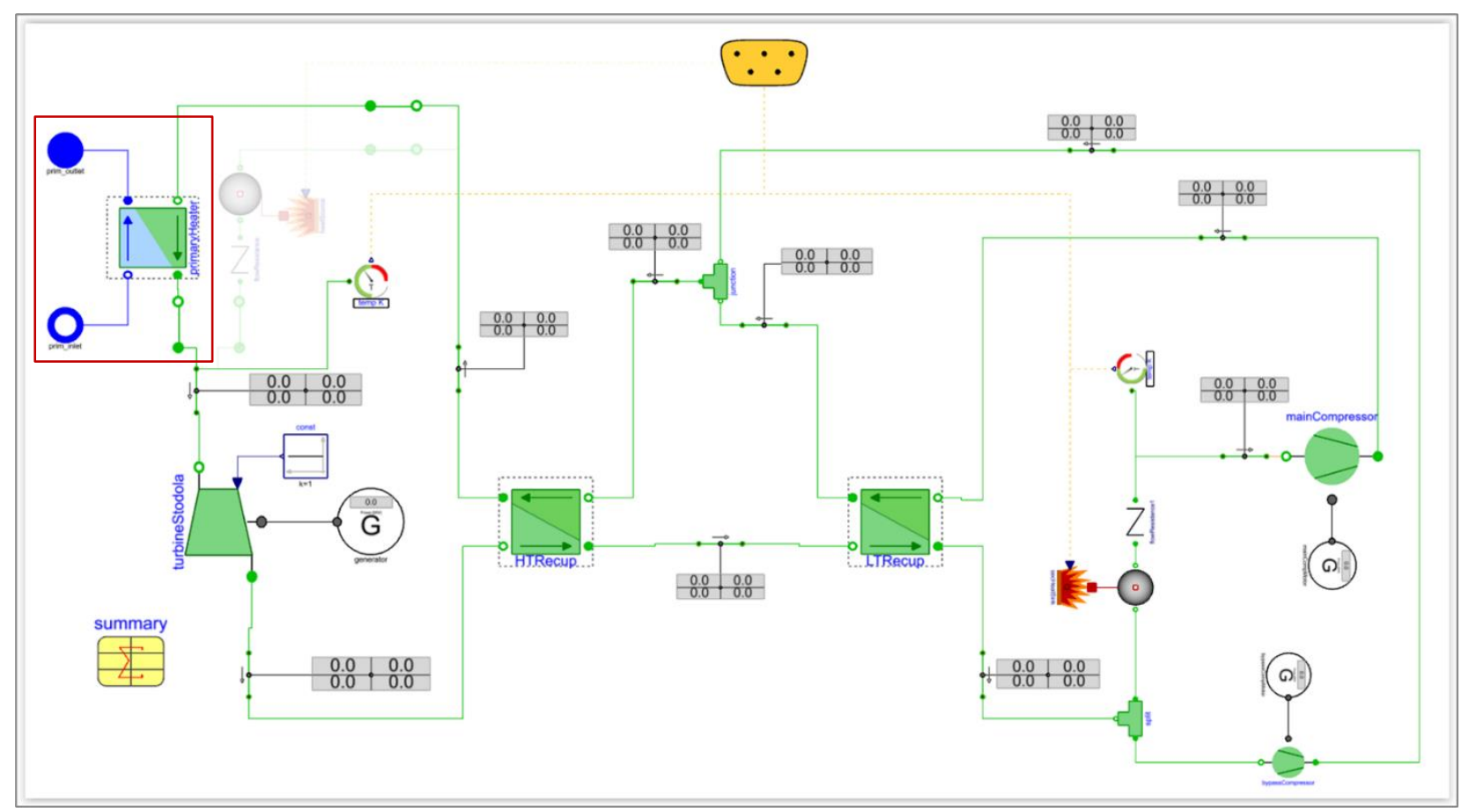

Figure 3. Brayton cycle with Heat exchanger as primary heater

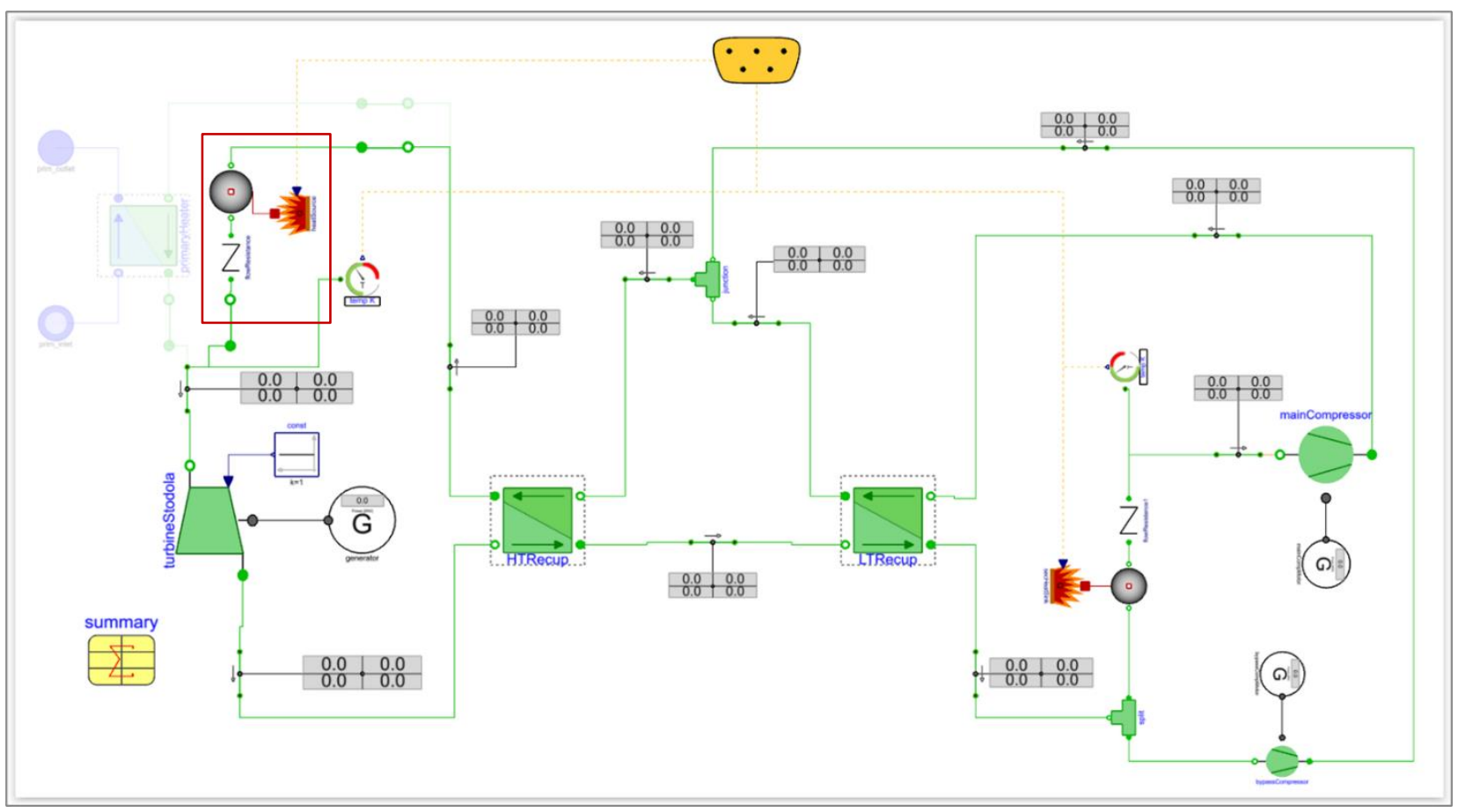

Figure 4. Brayton cycle with direct heat transfer to supercritical $\mathrm{CO}_{2}$ 


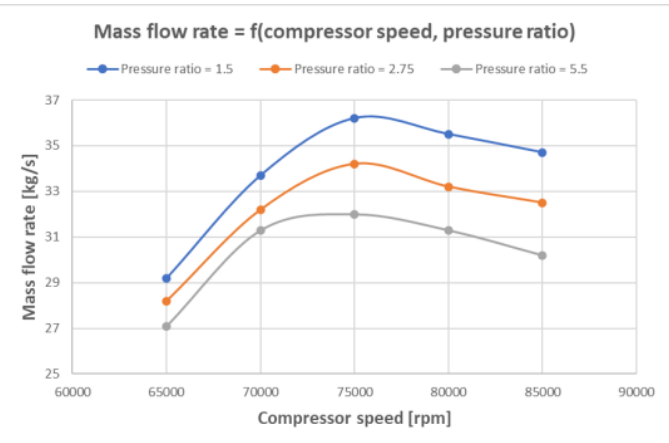

Figure 5. Bypass compressor mass flow map

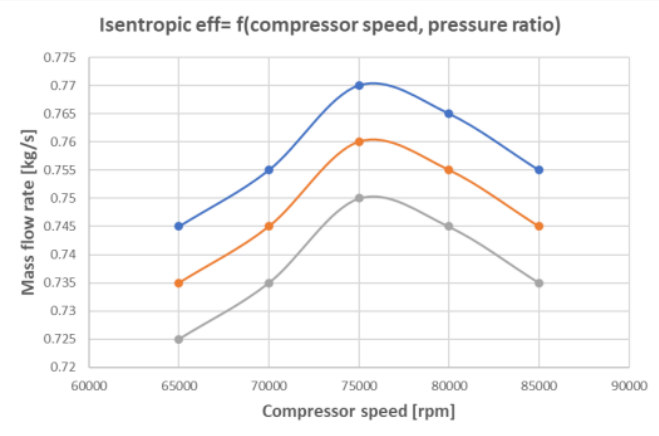

Figure 6. Bypass compressor isentropic eff map

Turbine model with flow according to Stodola's law is used with constant isentropic efficiency of $85 \%$. Generic counterflow two phase- two phase heat exchanger is used for modeling HTR and LTR. This heat exchanger can handle both single and two-phase refrigerant. Test benches are created for both the HX's and calibrated for the design point available in literature (Dennis, 2017). HTR test bench is shown below (Figure 7):

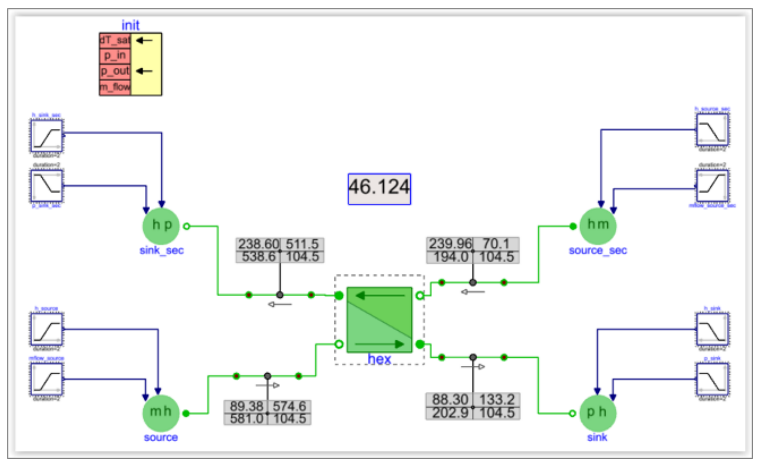

Figure 7. HTC test bench

\subsection{Brayton Cycle Control}

Sensor signals from relevant components are placed onto the control bus. A controller component is then connected to the primary heater and cooler heat sources. As shown in Figure 8 two PID controllers are used, one to provide heat to control turbine inlet temperature and other to control the temperature at the inlet of main compressor (to cool the fluid before entering compressor).

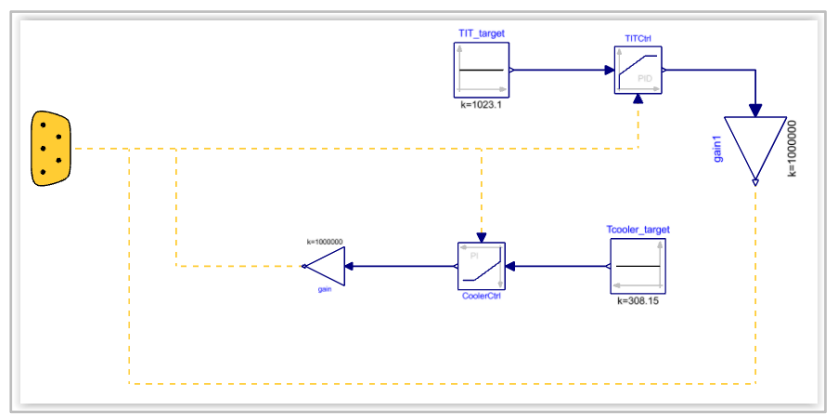

Figure 8. Brayton cycle controller

\section{Simulation Results}

Following the characterization of the system, a series of simulations were run by varying the turbine inlet temperature (TIT) in the range of 250 to $750{ }^{\circ} \mathrm{C}$. Cycle efficiency variation with respect to change in turbine inlet temperature can be seen in Figure 9.

For turbine inlet temperature of $750{ }^{\circ} \mathrm{C}$, power consumption of compressors and power generation by turbine are shown in Figure 10. Also heat transfer power of HTR, LTR, primary heater and cooler are shown in the same plot.

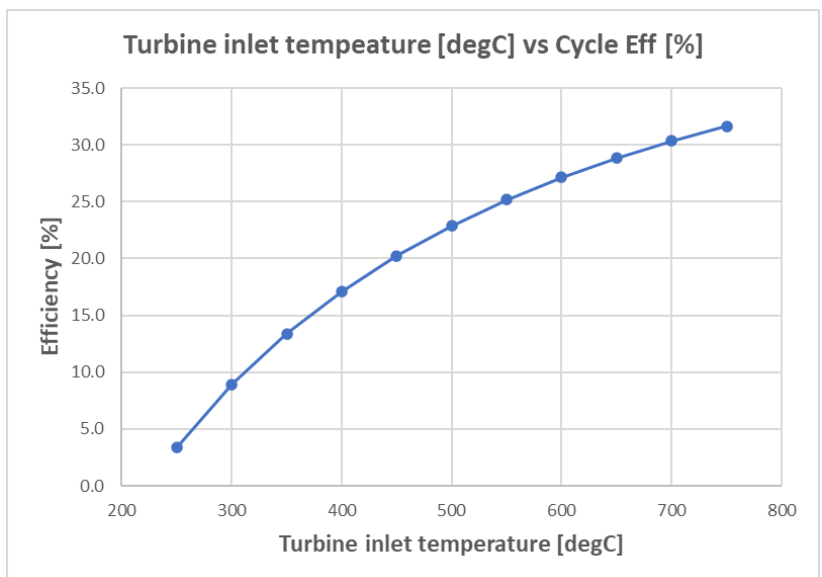

Figure 9. Turbine inlet temperature vs Cycle efficiency

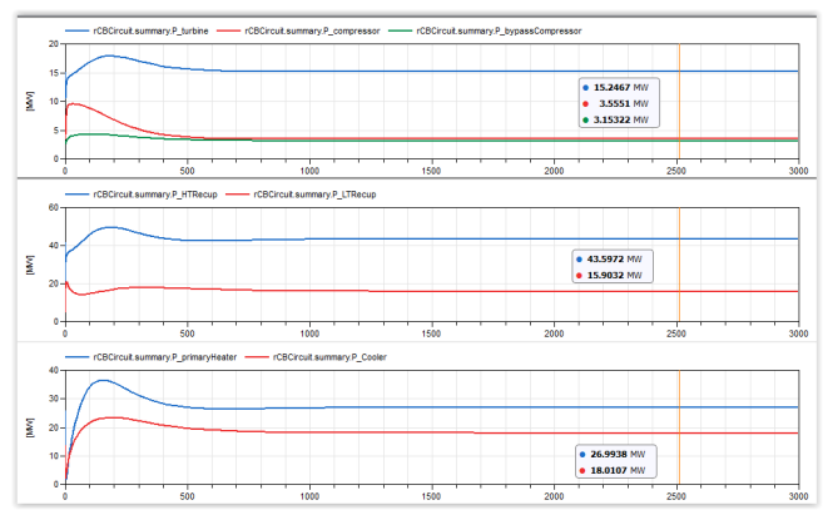

Figure 10. Different component powers 
Pressure enthalpy diagram for the cycle at $750{ }^{\circ} \mathrm{C}$ turbine inlet temperature is shown in Figure 11. Pink line indicates the flow through bypass compressor and mixing with the main compressor outlet flow.

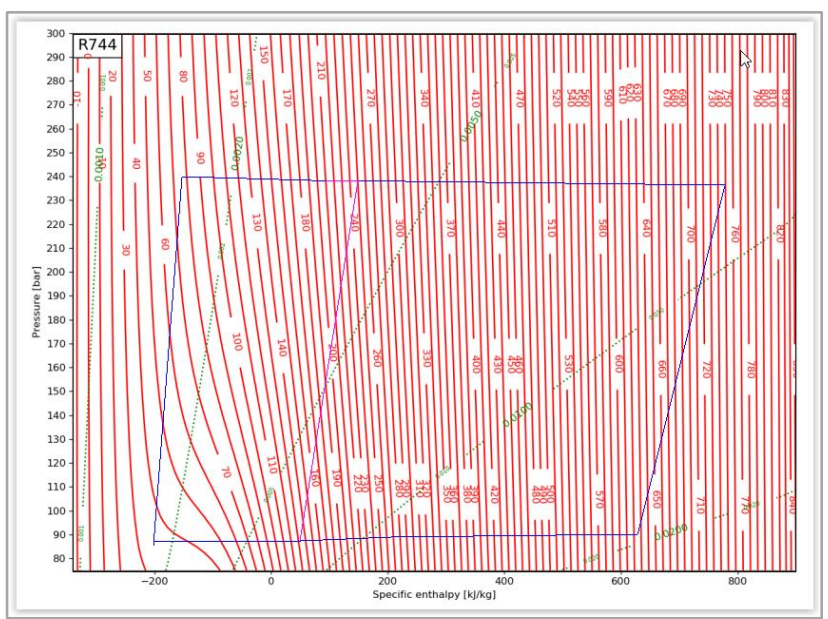

Figure 11. RCB PH diagram

Schematic of the cycle simulation with different visualizers is shown in Figure 12.

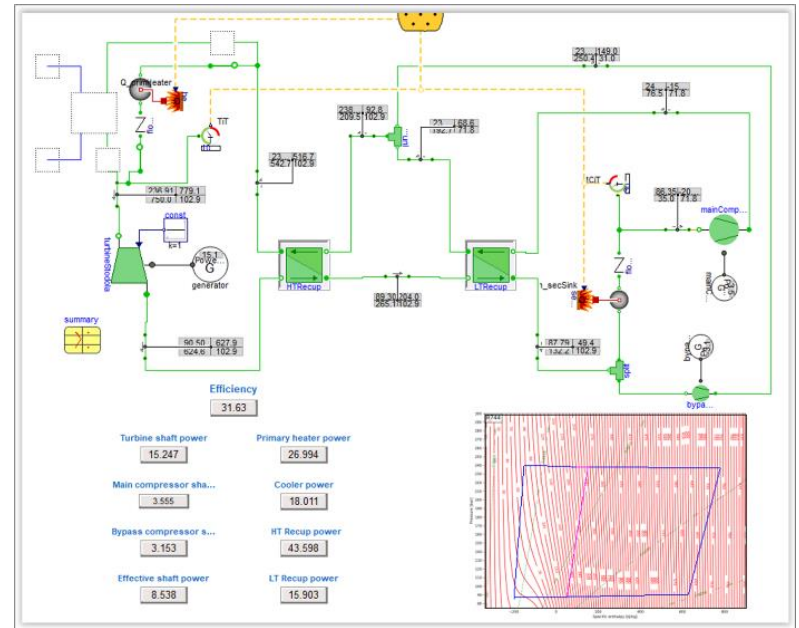

Figure 12. Cycle schematic with results

\section{CSP system}

As mentioned in the introduction, CSP thermal storage system model with Rankine cycle is already available. This model is modified such that working cycle can be interchanged between Rankine and Brayton cycles as shown in Figure 13.

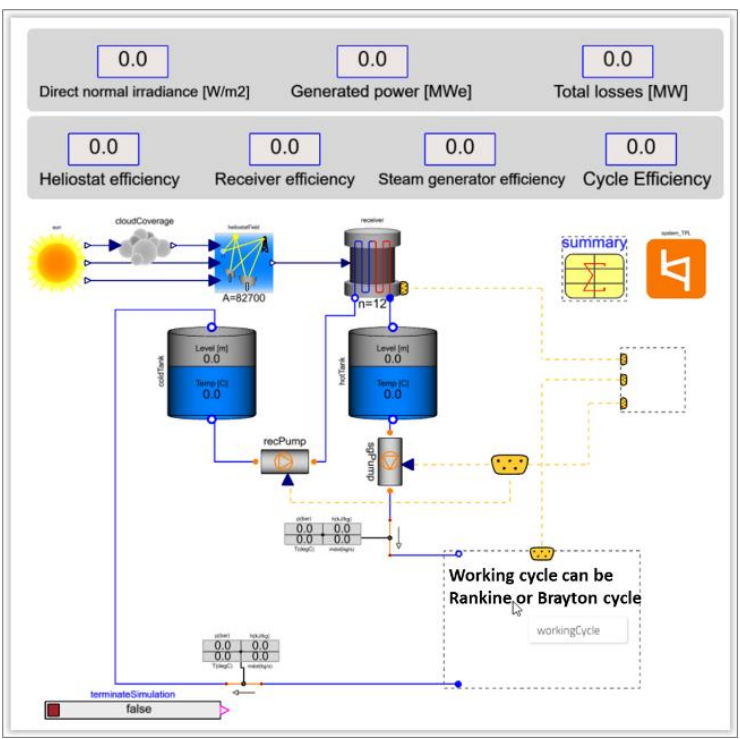

Figure 13. CSP system with flexible working cycle

CSP thermal storage system with Rankine cycle and Brayton cycle are shown in Figure 14 and Figure 15 respectively. In the CSP system with Brayton cycle, heat exchanger is used as primary heater for interchanging heat between Molten salt and supercritical $\mathrm{CO}_{2}$. As this option to change the routing through heat exchanger is already available, there is no requirement of modifying the original cycle.

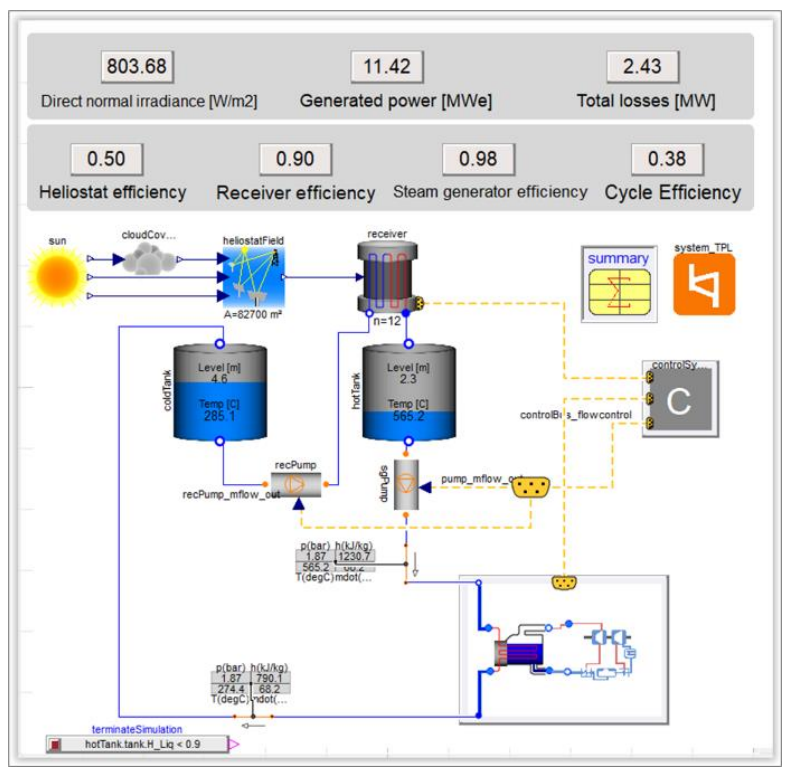

Figure 14. CSP system with Rankine cycle 


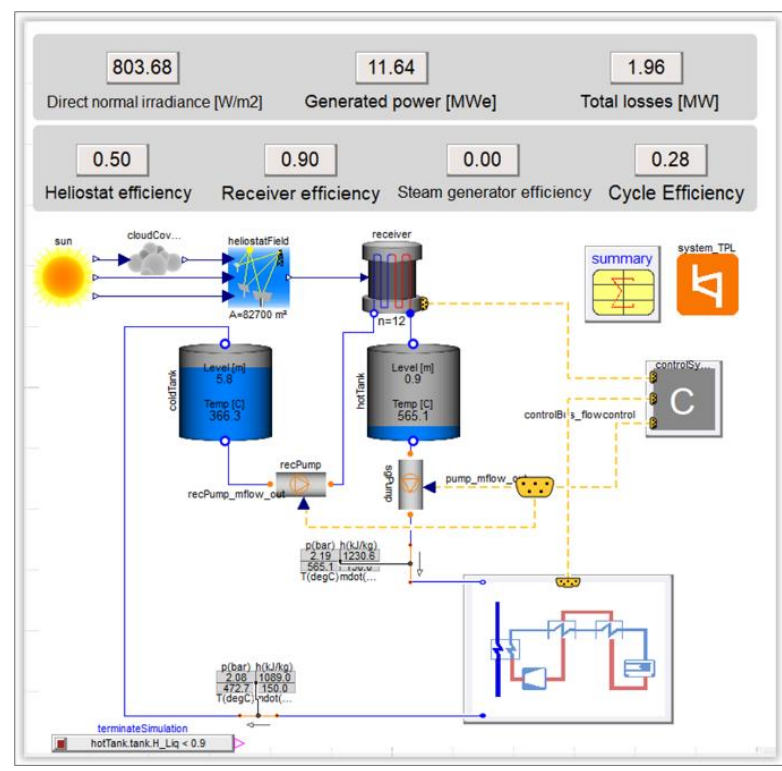

Figure 15. CSP system with Brayton cycle

As can be seen from the visualizers, models are run under similar conditions on the solar plant side. And we can observe the cycle efficiencies for the Rankine and Brayton cycles. As the components are not characterized by the actual maps, the results cannot be used for comparison. But the idea is to show how different cycles can be used along with CSP system to evaluate the performance and efficiency of the system.

\section{Summary}

This paper describes an effort to develop an analytic platform for recompression Brayton cycle to evaluate the performance and efficiency under different operating conditions. This analytic platform allows rapid virtual prototyping to evaluate the potential of recompression Brayton cycle under different operating conditions and for different system sizing. As expected with increase in turbine inlet temperature, cycle efficiency is increasing. It is also shown how the Brayton cycle can be easily connected to CSP thermal storage system for evaluating the electric power generation through solar power. Also modular structure of Modelica language is taken advantage of to choose between connecting CSP thermal storage system to either Rankine or Brayton cycles. This helps in doing several studies side by side and for comparing the performances.

Future work on this model includes opportunities for better system characterization if data on the actual system can be obtained. In particular, actual characterization of the compressors, turbine and heat exchangers would greatly improve model accuracy. In this work results are shown for steady state simulations, future work includes dynamic response of the system under varying boundary conditions. Further study can also include comparison between the
Ranking cycle and Brayton cycle in case actual system data is available for both the cycles.

\section{References}

Richard Dennis (2017). Overview of Supercritical Carbon Dioxide Based Power Cycles for Stationary Power Generation. International Seminar on Organic Rankine Cycle Power Systems; Politecnico di Milano; Milano Italy

Johan Edman, Johan Windahl (2015). Dynamic Modeling of a Central Receiver CSP system in Modelica. Proceedings of the 11th International Modelica Conference, pp. 586594

Jim Pasch, Tom Conboy, Darryn Fleming, and Gary Rocahu (2012). Supercritical $\mathrm{CO}_{2}$ Recompression Brayton Cycle: Complete Assembly Description. Sandia National Laboratories Report

Modelon AB, Lund, Sweden. (2020). Vapor Cycle Library Vapor Cycle Library | Modelica Library Built by Modelon

Modelon AB, Lund, Sweden. (2020). Thermal Power Library Thermal Power Library | Modelica Library Built by Modelon 